\title{
GROWTH AND EMIGRATION OF THIRD-STAGE LARVAE OF HYSTEROTHYLACIUM ADUNCUM (NEMATODA: ANISAKIDAE) IN LARVAL HERRING CLUPEA HARENGUS
}

\author{
Juan Antonio Balbuena, Egil Karlsbakk ${ }^{\star}$, Anne Mette Kvenseth ${ }^{\star}$, Monica Saksvik , and Are Nylund ${ }^{\star}$ \\ Marine Zoology Unit, Cavanilles Institute of Biodiversity and Evolutionary Biology, University of Valencia, Paterna Campus, P.O. Box 22085, \\ 46071 Valencia, Spain
}

\begin{abstract}
The growth and emigration of Hystherothylacium aduncum in laboratory-reared herring larvae Clupea harengus was studied. Experimental infections of 36-day-old herring larvae resulted in 126 hosts infected with $306 \mathrm{H}$. aduncum larvae. Regression analyses showed a significant worm emigration from the rectum to the head of the fish, accompanied by an increase in worm body length. The emigration was independent of worm intensity, which suggests an ontogenetic process. Some worms departed from this pattern by moving posteriorly or by penetrating into the muscle, and in 5 cases, the larvae were observed to leave living fish. This individual variation has not been observed in previous studies and might be explained by host signals related to condition or development stage. Indirect evidence suggested parasite-induced mortality in the tanks due to the emigrations because only 4 of the 126 infected fish survived 8 days postinfection; the emigration of $H$. aduncum affected vital organs, such as the heart and brain, and the larvae penetrating or leaving the host's tissues can cause extensive damage to the delicate herring larvae.
\end{abstract}

Although different studies have shown that larvae and juveniles are generally more vulnerable to disease than older fish (Munro et al., 1983), information of parasite pathogenicity on young fish is lacking. Considering metazoan parasites, the few studies available point to mechanical damage as a major reason for juvenile mortality. Examples include trematodes, both as adults (Ivanchenko and Grodzdilova, 1971, 1981, 1985; Bristow, 1990) and as larval stages (MacKenzie and Liversidge, 1975; Maillard et al., 1980; Lauckner, 1984) and larval crustacea (Rosenthal, 1967). One of the best documented cases of parasite-induced mechanical damage in larval fish corresponds to the anisakid nematode Hysterothylacium aduncum. This parasite is one of the most common helminths in marine teleosts throughout the world, at least in temperate and cold waters $(\mathrm{Na}-$ vone et al., 1998). The taxonomy of this nematode is currently unsettled, as it may represent a complex of sibling species (Køie, 1993). In North Atlantic waters, most authors recognize a single species, but in a recent revision, Petter and Cabaret (1995) distinguished 3 morphologically distinct entities $(H$. auctum, H. aduncum aduncum, and $H$. aduncum gadi). Although $H$. aduncum sensu lato is thought of as slightly pathogenic or nonpathogenic, in adult fish (Berland, 1987), it has been observed that a single larva can kill fish larvae (Rosenthal, 1967; Bristow, 1990). Rosenthal (1967) showed that Contracaecum sp. (probably H. aduncum) killed laboratory-reared larval herring fed with wild zooplankton. Mortality seemed primarily caused by violent movements of the nematode damaging the gut. Likewise, Bristow (1990) reported mortality produced by $H$. aduncum in young, farmed halibut Hippoglossus hippoglossus. Histozoic emigration from the visceral cavity to the head of the host accounted for the casualties. The purpose of the present paper is to study the growth and emigration of H. aduncum gadi in experimentally infected larval herring. The results will disclose new information on the ontogenetic behavior of this parasite that will be discussed in relation to mechanical damage in larval fish.

Received 22 June 1999; revised 10 May 2000; accepted 10 May 2000. * Department of Fisheries and Marine Biology, Fish Diseases Group, University of Bergen, High Technology Center, 5020 Bergen, Norway.

\section{MATERIALS AND METHODS}

\section{Experimental conditions, definitions, and general criteria}

Unless otherwise stated, the experiments were carried out at 11-13 $\mathrm{C}$ in seawater (34\%o salinity). To prevent accidental parasite infection by food ingestion, the water employed, both in the experiments and cultures, was passed through a $0.1-\mathrm{mm}$ mesh filter, and all zooplankton used either as food or as intermediate hosts were reared in the laboratory from the egg stage. All experiments were carried out at the Department of Fisheries and Marine Biology, University of Bergen, Norway.

Ecological terms describing parasite infection conform to Bush et al. (1997), and 'emigration' is used as defined in Crompton (1973). Mean values are given followed by the SD in parentheses.

\section{Source and culture of herring larvae}

Herring eggs were stripped from 2 females and milt from 5 males caught at Herdlefjorden (western Norway) on 25 September 1996. Subsequent dissection of the broodstock fish revealed no apparent sign of disease. The eggs were incubated in circulating seawater. Fifty percent hatching (day 0 of larval development) occurred on 8 October 1996. The hatched herring larvae were transferred to 500-L aerated tanks, where they were fed rotifers Brachionus plicatilis from 3 to 20 days of age and Artemia franciscana nauplii from 21 days of age to the start of the experimental infections. Details on egg incubation and source and culture of food organisms are given in Kvenseth et al. (1997).

\section{Source and culture of $\boldsymbol{H}$. aduncum larvae}

Eggs were obtained from 6 gravid H. aduncum females collected from saithe Pollachius virens caught near Bergen (western Norway). Fish of this species were the only sampled around Bergen that provided sufficient numbers of $H$. aduncum gravid females for our experiments The specimens were identified as $H$. aduncum gadi following Petter and Cabaret (1995). (Morphometric data and criteria for nematode identification are given in Balbuena et al. [1998].)

The eggs were incubated in petri dishes at $5 \mathrm{C}$, and Acartia tonsa copepods were used as first intermediate hosts. (See Balbuena et al [1998] for details on egg incubation and culture and infection of copepods.) Approximately 4,000 copepods were exposed to about 4,000 hatched third-stage larvae in an aerated 40-L tank at $20 \mathrm{C}$ (copepod infection tank). The copepods were used for infection of larval herring 12 days later; then, the prevalence was estimated as $57 \%$ and the mean abundance as $0.8(0.9)(\mathrm{n}=35)$.

\section{Infection of herring larva}

Having overcome the critical stage of first feeding, 200 herring larvae were transferred each to 2,20-L aerated experimental tanks (here, tanks $\mathrm{E} 1$ and E2). The herring larvae were 36 days old, and the mean length was $18.6(2.1) \mathrm{mm}(\mathrm{n}=18)$. Approximately 1,400 copepods were added to each tank. In tank E1, all copepods came from the copepod infection tank, whereas in tank E2, copepods were mixed 1:1 with un- 


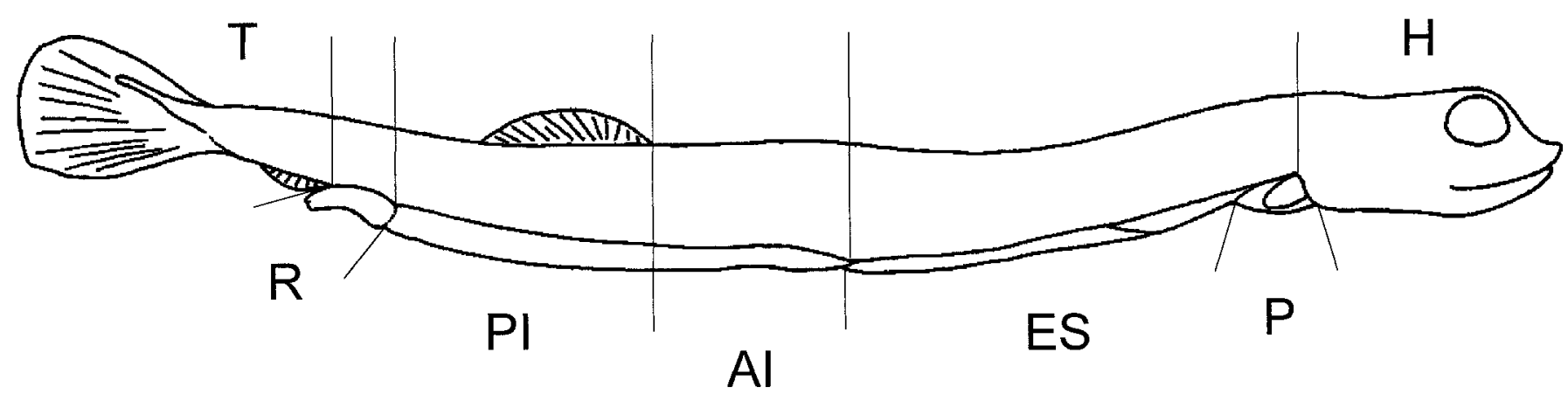

\section{$2 \mathrm{~mm}$}

FIGURE 1. Sites considered in studying the distribution of third-stage Hysterothylacium aduncum larvae in the herring larvae. Abbreviations: AI, anterior intestine; ES, esophagus and stomach; H, head; P, pericardial cavity; PI, posterior intestine; R, rectal pouch; T, tail.

infected copepods. This yielded a ratio of infected copepods to larval herring of approximately 4:1 and 2:1 in tanks E1 and E2, respectively. Dead herring larvae were collected daily and recorded. Three samples of living larvae were also taken to control for pre- and postmortem differences in the behavior of the H. aduncum larvae. First, 10 individuals were collected 0.5 days postinfection (PI) from each tank. Second, moribund fish were collected from E1 and E2 $(\mathrm{n}=7$ and 6, respectively) 3 days PI. These individuals were identified by swimming close to the bottom showing slow escape response. Finally, the third sample consisted of individuals surviving the experiments after 8 days PI $(\mathrm{n}=$ 21 and 23 from E1 and E2, respectively).

\section{Site and size patterns}

The herring larva were preserved in formalin, cleared in glycerol, and examined for $H$. aduncum larva under a stereo microscope. The site of each nematode was recorded considering 7 general locations along the longitudinal axis of the herring larva: tail (postanal location), rectal pouch, posterior intestine, anterior intestine, stomach-esophagus, pericardial cavity, and head (Fig. 1). In addition, we noted whether the worm was in the body cavity or totally or partly penetrating the muscle. To measure the length of the nematodes, the infected herring larvae were mounted in glycerol and examined under a light microscope, the outline of each worm being drawn with the aid of a drawing tube. We used a scanner to convert such sketches, together with a scale of reference, into digital images, which were then processed with a computer program (Image Pro Plus for Windows 2.1, Media Cybernetics, 1993-1994) to compute the length of each outline. This procedure is fast and convenient but involves a systematic error since the outlines are 2-dimensional representations of 3-dimensional, coiled larvae. This error may underestimate larval length, affecting more severely short (younger) larvae because they tended to coil more than the larger ones. However, to minimize this problem, measurements were not taken of extremely coiled or unclearly seen larvae.

\section{Statistical analyses}

We used a site score method based on Moore and Simberloff (1990) to characterize the distribution of larval worms along the herring larvae. A consecutive rank was assigned to each location, from posterior to anterior, ranging from 1 (rectal pouch) to 6 (head). (The tail was excluded from the analysis because it was rarely occupied.) Each worm scored with its location, the mean site score $(M)$ being used as a descriptor of the worm distribution. Thus, $M$ can vary from 1 (all worms located in the rectal pouch) to 6 (all worms located in the head). We also evaluated worm site preference with Levins' standardized measure of niche breadth $(B)$ (Krebs, 1989), considering each site (except the tail, see above) as a resource. The measure ranges from 0 (all individuals occur in one site) to 1 (worms occupy all the locations in equal numbers). Therefore, $B$ can also be regarded as an estimator of worm dispersion along the herring larva.

Stepwise multiple linear regressions were used to identify which variables can predict significant changes in $M$ and $B$ in the dead herring larvae. Our primary interest was to establish whether time PI was a predictor of $M$ and $B$, but the effect of worm intensity was also tested to control for density-dependent effects (Aznar et al., 1997). In addition, potential differences between tanks E1 and E2 were considered by incorporating a dummy variable (Draper and Smith, 1981). The same statistical procedure was used to study changes in the body length of $H$. aduncum in the dead herring larvae. The starting variables were time PI, site score (1 to 6), and experimental tanks (coded as a dummy variable). To ensure independence of the length observations, the analysis was performed considering 61 dead herring larvae for which only 1 nematode larva could be measured. This data set consisted of 44 single, 9 double, 7 triple, and 1 quadruple infection. To account for density-dependent effects on larval length, an additional dummy variable was incorporated to distinguish between single and multiple infections. In all regression analyses, the dependent variables and worm intensity were log-transformed for linearity and homoscedasticity, and the suitability of each model was explored by residual analyses.

Differences in $B, M$, worm intensity, and length between dead and alive herring larvae were evaluated by means of Student's $t$-tests, with log-transformed variables for normality and homoscedasticity. Pairwise comparisons were made between chronologically close samples, so the 3 samples of living herring $0.5,3$, and 9 days PI were compared respectively to those of dead herring 1,3 , and 8 days PI. Differences between tanks were not considered because of the small sample sizes, but we checked that the number of herring was not biased toward either tank.

\section{RESULTS}

In all, $306 \mathrm{H}$. aduncum larvae occurred in 126 larval herring (198 and 108 worms from 74 and 52 herring larvae in tanks E1 and E2, respectively). Single infections represented $42 \%$ of the total (30 and 23 cases in tanks E1 and E2, respectively), doubles $24 \%$ (15 herring in each tank), and triples $16 \%$ (9 and 2 cases in E1 and E2, respectively). The maximum number of larvae found in a single host was 13 . The most frequently occupied site by $H$. aduncum was the posterior half of the intestine, whereas the tail was the least preferred site. This pattern was observed both globally and on an individual host basis (Fig. 2). The nematode larvae also occurred in vital organs, such as the pericardial cavity and the brain. The average $M$ across herring larvae was 2.54 (1.13), reflecting the preference of $H$. aduncum to locate along the intestine. In fact, about $80 \%$ of the worms occurred either along the rectal or the intestinal region. Usually, the larvae were found in the body cavity, particularly dorsal to the digestive tract, but 42 (14\% of the total) were totally or partly penetrating the muscle. Larvae within the 


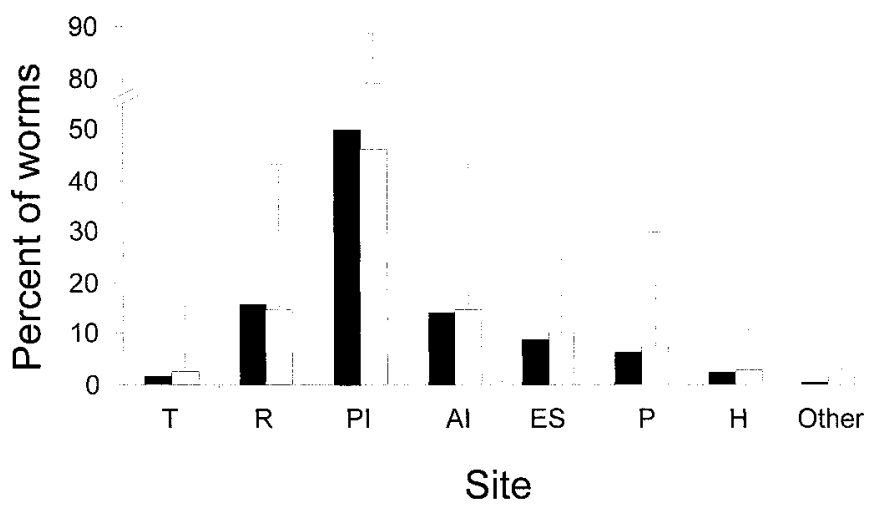

FIGURE 2. Proportion of third-stage Hysterothylacium aduncum larvae in each of the sites considered (see Fig. 1). Filled and blank bars correspond respectively to pooled and mean values of the 126 infected herring larvae. Error bars of mean percentages represent +1 SD. Abbreviations as in Figure 1.

muscle occurred in 36 individuals and represented an average of $57 \%$ (32.4) of the total in these hosts. In 10 cases, they were single infections. All but 1 of the larvae penetrated the muscle at either rectal or intestinal level. In 5 additional cases, 7 larvae protruded from the hosts' body wall. All were from live herring (i.e., 1 on day $0.5 \mathrm{PI}$ and 4 on day $3 \mathrm{PI}$ ). Three worms in 3 dead hosts could not be allocated to any site because they were found either on the external surface or near the host. Time PI was the only significant predictor of $M$, and the regression model indicated a weak but significant monotonic increasing trend (Table I). By contrast, $B$ decreased with time PI, and most of the variation was accounted for by a positive relationship with worm intensity (Table I). No $t$-tests revealed significant differences of $B, M$, mean intensity, or worm length between the samples of dead and living herring.

The length of the $H$. aduncum larvae ranged from 0.4 to 2.4 $\mathrm{mm}$. Figure 3 suggests an anteriad increase of larval length with the site occupied in the host. However, larvae located in the pericardial cavity seemed shorter than expected, although the small sample size precludes evaluating whether this pattern is significant. In fact, the length data fitted well to a linear regression model, site being the variable that accounted for most of the variation. Additionally, time PI was a significant predictor of larval length but only in E2 (Table I).

\section{DISCUSSION}

In North Atlantic waters, $H$. aduncum gadi is mostly found in gadid fishes, whereas $H$. aduncum aduncum is more common in other fish, including clupeiforms like herring (Petter and Cabaret, 1995). Although this raises the question of whether the host-parasite system studied here is relevant under natural conditions, the area where herring hatch in western Norway overlaps with that of infected gadids (Berland, 1961). Consequently, it is probable that herring larvae can be infected by $H$. aduncum gadi by preying on local zooplankton. Besides, the general behavior of the nematodes reported here is similar to that previously described for H. aduncum, both in larval herring (Rosenthal, 1967) and halibut (Bristow, 1990) infected with wild zooplankton. Both Rosenthal (1967) and Bristow (1990) concur in reporting an anteriad emigration of the $H$. aduncum larvae in
TABLE I. Summary statistics of stepwise multiple linear regressions describing variation in the distribution and growth of third-stage Hysterothylacium aduncum larvae in herring larvae. Variables accounting for significant variation of the dependent variable are listed in descending order of importance (as denoted by the change in $R^{2}$ ).

\begin{tabular}{clrcc}
\hline $\begin{array}{c}\text { Dependent } \\
\text { variable* }\end{array}$ & \multicolumn{1}{c}{$\begin{array}{c}\text { Predictor } \\
\text { variables }\end{array}$} & Slope & Intercept & \multicolumn{1}{c}{$R^{2}$} \\
\hline$M$ & Time PI & 0.084 & 0.612 & 0.13 \\
$B$ & Intensity & 0.511 & 0.000 & 0.54 \\
& Time PI & -0.343 & & 0.56 \\
$L$ & Site & 0.104 & -0.581 & 0.21 \\
& Time PI $\times$ tank & 0.049 & & 0.29 \\
\hline
\end{tabular}

* M, mean site score; B, Levins' standardized niche breadth; L, length of $H$. aduncum larvae; $\mathrm{Pl}$, postinfection.

young fish. At a given time, the worms leave the body cavity and move toward the host's head. In larval herring, the nematodes may penetrate the pericardial cavity, which likely disturbs heart function (Rosenthal, 1967). All these observations were confirmed by the present study, as most worms seem to move along the longitudinal axis of the herring larvae from the rectal pouch to the head. This is supported by the significant increase of the mean site score with time PI. The emigration was not significantly affected by the number of worms, which militates against movements driven by intraspecific competition and, rather, suggests a genuine ontogenetic cause. The positive relationship between worm dispersion $(B)$ and intensity of infection also conforms to this idea. Although this pattern has usually been interpreted as evidence for density-dependent intraspecific competition, worm populations undergoing an ontogenetic emigration may expand their distributions with intensity simply because large infrapopulations can result from a mixture of new and old infections (Aznar et al., 1997). This possibility is further substantiated by the weak but significant decrease of worm dispersion with time PI. This variable, as considered here, does not necessarily reflect the time when each individual herring larva became infected, but the span between the first

\section{5}

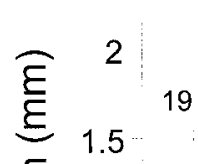

둥

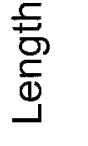

0.5

\section{0}

19

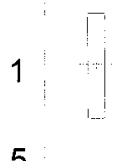

88

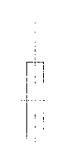

29
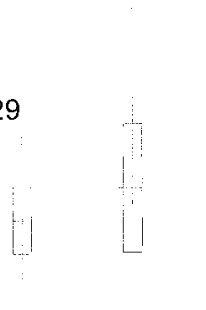

9

18
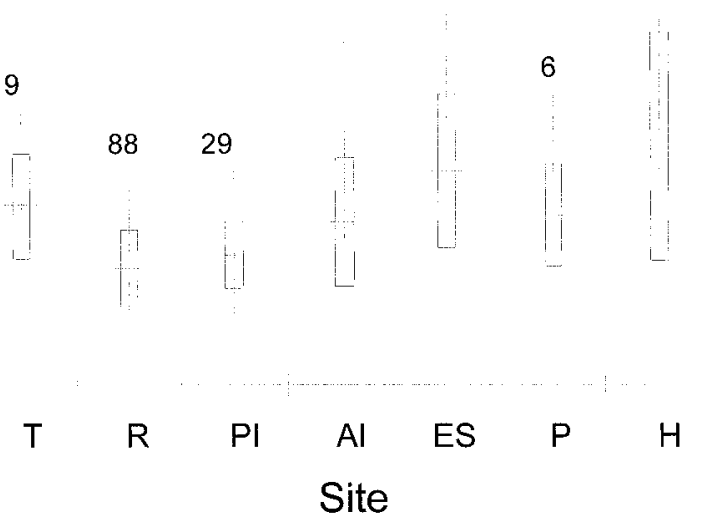

FIGURE 3. Body length of third-stage Hysterothylacium aduncum larvae in each of the sites considered (see Fig. 1). Mean values are shown as horizontal bars and ranges (minimum-maximum) as vertical bars. Boxes correspond to $\pm 1 \mathrm{SD}$. Abbreviations as in Figure 1 . 
exposure to the infected copepods and sampling of the herring larvae. The probability of new infections in the tanks should decrease with time PI as the infected copepods are eaten; therefore, if the ontogenetic emigration model is correct, worm distributions are expected to contract as older infections move anteriorly.

The anteriad emigration of $H$. aduncum was accompanied by an increase in body length. Judging from the mean values per site, the larvae doubled their lengths from the moment they penetrated the rectal pouch until they reached the head of the herring larva. Unfortunately, we cannot compare our data with other work because previous quantitative data are missing. According to the regression model, site is a good predictor of nematode length, whereas time PI plays an ancillary role, and only in 1 of the tanks (Table I). The poor predictive value of growth by a time variable might seem surprising, but this is perhaps justified by the nature of time PI as explained above. Larval growth was similar in single and multiple infections, which is also evidence against any density-dependent effect.

The present study suggests more variation in the emigratory pathways than previously reported. Some worms (about 17\%) seemed to stop traveling and either move into the muscle or leave the host, whereas others $(2 \%)$ moved backward and penetrate the tail. We cannot say much about the reasons for such variation because nothing is known about the proximal causes involved. Processes such as ontogenetic emigrations by helminths seem to be governed by the evolution of optimal fixed behaviors in response to the fairly predictable conditions within their hosts (Sukhdeo and Sukhdeo, 1994). However, completely unvarying motor patterns are unlikely to evolve because evidence shows that helminths can detect slight alterations in the host's signals, and they modulate their response accordingly (Sukhdeo and Sukhdeo, 1994). Therefore, the decision on whether to move on or to penetrate the tissues can be based on signals such as host condition or development stage.

Some aspects reported here differ greatly from Rosenthal's (1967) study, which indicated that mortality occurred on day 11 PI, whereas nearly $90 \%$ of our larvae died with 8 days PI. Kvenseth et al. (1997) monitored the growth of the sib herring larvae not used in this study, noting high mortality between 30 and 50 days after hatching (i.e., within the age span of our experiments). Therefore, we cannot say how much of the mortality in the experimental tanks is directly attributable to $H$. aduncum. The fact that most worms concentrated at the rectum and intestine level (Fig. 2) suggests that some herring larvae died before the emigration was completed. However, at least 4 pieces of evidence indicate that parasite-induced mortality occurred within the span of our study. First, only 4 of the 126 infected fish survived after day 8 PI, which suggests higher mortality among the infected individuals. Second, the emigration of worm larvae affected vital organs such as the heart and brain of the fish. The relatively shorter length of the worms in the pericardial cavity may be indicative of mortality. Third, those penetrating the musculature should probably impair swimming, cause considerable mechanical damage, and hence mortality. To our knowledge, this is the first record of H. aduncum larvae penetrating the musculature of larval fish (see Rosenthal [1967] and Bristow [1990]). The proximate reasons accounting for this behavior are unknown but an intensity-dependent effect does not seem likely, as 10 of the 36 cases repre- sented single infections. Fourth, the nematode larvae breaking through the body wall should undoubtedly be fatal for the delicate herring larvae. In fact, in young, farmed halibut, mortality is caused by $H$. aduncum larvae perforating and leaving through the eye orbit (Bristow, 1990). If the tendency to leave living hosts is common, it is noteworthy that this nematode can be an important mortality cause among fish larvae and that field studies based on samples of dead hosts might underestimate the prevalence or abundance of the parasite.

An important question is whether the emigration and growth patterns described here are relevant to herring or other fish larvae in natural conditions. Clearly, additional work is needed to provide better answers and to account for differences between this and previous work. Further studies should evaluate factors that may influence the behavior of $H$. aduncum larvae, such as potential differences between the $H$. aduncum morphotypes; experimental conditions; presence of stressors, morbidity agents, or other mortality causes; and variations with host development and species.

\section{ACKNOWLEDGMENTS}

We thank Frank Midtøy for invaluable technical assistance and Javi Aznar for helpful comments and suggestions. The experiments were conducted under the Large Scale Facility for Marine Pelagic Food Chain Research, funded by the European Commission (contract ERBFMGECT950013).

\section{LITERATURE CITED}

Aznar, F. J., J. A. Balbuena, A. O. Bush, and J. A. Raga. 1997. Ontogenetic habitat selection by Hadwenius pontoporiae (Digenea: Campulidae) in the intestine of franciscanas (Cetacea). Journal of Parasitology 83: 13-18.

Balbuena, J. A., E. Karlsbakk, M. SAKsvik, A. M. Kvenseth, and A. NYLUND. 1998. New data on the early development of Hysterothylacium aduncum (Nematoda, Anisakidade). Journal of Parasitology 84: 615-617.

Berland, B. 1961. Nematodes from some Norwegian marine fishes. Sarsia 2: $1-50$

- 1987. Helminth problems in sea-water aquaculture. In Parasites and diseases in natural waters and aquaculture in Nordic countries, E. Stenmark and G. Malmberg (eds.). Zoo-tax, Naturhistoriska Riksmuseet, Stockholm, Sweden, p. 56-62.

Bristow, G. A. 1990. Dødelighet hos kveitelarver og yngel i startfôringsfasen. Norsk Fiskeoppdrett 15: 40-43.

Bush, A. O., K. D. Lafferty, J. M. Lotz, and A. W. Shostak. 1997. Parasitology meets ecology in its own terms: Margolis et al. revisited. Journal of Parasitology 83: 575-583.

Crompton, D. W. T. 1973. The sites occupied by some parasitic helminths in the alimentary tract of vertebrates. Biological Reviews 48: $27-83$.

DRAPER, N. R., AND H. SMith. 1981. Applied regression analysis. Wiley, New York, 709 p.

IvanCHENKo, O. F., AND T. A. GrozDILOVA. 1971. Parasites of young of the White Sea herring (Clupea harengus pallasi Natio Maris-Albi Berg) reared under artificial conditions. Parazitologiya 5: 233-236. [In Russian.]

, AND — 1981. The infections of larvae of the White Sea herring reared under experimental conditions with the trematode Lecithaster gibbosus (Hemiuridae). Parazitologiya 15: 132-134. [In Russian.]

- AND 1985. Infestation rate of the young of White Sea herring reared under experimental conditions and caught in the sea, by trematodes and their pathogenic effect. In Parasitology and pathology of marine organisms of the world ocean, W. J. Hargis Jr. (ed.). NOAA Technical Report NMFS 25, Seattle, Washington, p. 65 . 
KøIE, M. 1993. Aspects of the life cycle and morphology of Hysterothylacium aduncum (Rudolphi, 1802) (Nematoda, Ascaridoidea, Anisakidae). Canadian Journal of Zoology 71: 1289-1296.

KreBs, C. J. 1989. Ecological methodology. Harper Collins, New York, $654 \mathrm{p}$.

Kvenseth, A. M., F. Midtøy, J. Balbuena, And A. Nylund. 1997. Kultivering av sildelarver (Clupea harengus) uten bruk av villfanget zooplankton. Instittut for Fiskeri og Marinbiologi Rapport 15, University of Bergen, Bergen, Norway, $18 \mathrm{p}$.

LAUCKNER, G. 1984. Impact of trematode parasitism on the fauna of a North Sea tidal flat. Helgoländer Meeresuntersuchungen 37: 185199.

MacKenzie, K., AND J. M. Liversidge. 1975. Some aspects of the biology of cercaria and metacercaria of Stephanostomum baccatum (Nicoll, 1907) Manter, 1934 (Digenea: Acanthocolpidae). Journal of Fish Biology 7: 247-256.

Maillard, C., A. Lambert, and A. Raibaut. 1980. Nouvelle forme de distomatose larvaire. Étude d'un Trématode pathogène pour alevins de Daurades (Sparus aurata L., 1758) en écloserie. Comptes Rendues de l'Academie de Sciences de Paris, Série D 290: 535-538.

Moore, J., AND D. SimberLOFF. 1990. Gastrointestinal helminth communities of bobwhite quail. Ecology 71: 344-359.

Munro, A. L. S., A. H. MCVicar, AND R. Jones. 1983. The epidemiology of infectious disease in commercially important wild marine fish. Rapports et Procès-verbaux des Réunions du Conseill international pour l'Exploration de la Mer 182: 21-32.

Navone, G. T., N. H. SARdella, AND J. T. Timi. 1998. Larvae and adults of Hysterothylacium aduncum (Rudolphi, 1802) (Nematoda: Anisakidae) in fishes and crustaceans in the South West Atlantic. Parasite 5: 127-136

Petter, A. J., And J. Cabaret. 1995. Ascaridoid nematodes of teleostean fishes from the eastern North Atlantic and seas of the north of Europe. Parasite 2: 217-230.

Rosenthal, H. 1967. Parasites of the herring (Clupea harengus L.) fed with wild plankton. Marine Biology 1: 10-15.

SuKHDEO, M. V. K., AND S. C. SuKhdeO. 1994. Optimal habitat selection by helminths within the host environment. Parasitology 109: S41-S55. 